\title{
Diagnostic evaluation of causes of bleeding per vagina in pregnancy through ultrasonography
}

\author{
Sumathy K. K.* \\ Department of Obstetrics and Gynecology, Mount Zion Medical College Hospital, Ezhamkulam, Adoor \\ Pathanamthitta, Kerala, India
}

Received: 25 February 2019

Accepted: 22 March 2019

* Correspondence:

Dr. Sumathy K. K.,

E-mail: dr.sumathyrajan@gmail.com

Copyright: ( $\odot$ the author(s), publisher and licensee Medip Academy. This is an open-access article distributed under the terms of the Creative Commons Attribution Non-Commercial License, which permits unrestricted non-commercial use, distribution, and reproduction in any medium, provided the original work is properly cited.

\begin{abstract}
Background: Vaginal bleeding is a common obstetric situation ranging from an insignificant episode to life threatening emergency. Ultrasonography is playing an increasing role in the diagnostic process. The objective of present study was to evaluate the uses of ultrasound as new diagnostic aid for patients of bleeding PV in pregnancy.

Methods: A hospital-based prospective study was conducted among 100 pregnant patients who have the problem of bleeding. A complete general physical and pelvic examination was done, and patients were then subjected to ultrasound examination. Epi info 7 software was used for statistical analysis. Chi- square test was used as the test of significance. $\mathrm{P}<0.05$ is considered statistically significant.

Results: Among these 100 cases, Incomplete abortion was the commonest cause of bleeding. This was observed in 15 cases $(27 \%)$. There were $8(20 \%)$ cases of complete abortion in the present study in the scan done on $<20$ weeks. Abruptio placenta was seen in $10(25 \%)$ cases as the most common cause in the scan after 20 weeks.

Conclusions: Ultrasound is a valuable tool in the differentiation of causes of first trimester vaginal bleeding. Ultrasound is helpful in the decision-making algorithm about the safe continuation of the pregnancy, timely intervention for abnormal pregnancy.
\end{abstract}

Keywords: Abortion, Per vaginal bleeding, Ultrasonography

\section{INTRODUCTION}

Ultrasonography is one of the most useful diagnostic tools in the field of modern medicine. Being noninvasive, safe and without hazards of radiation, it has gained wide acceptability, as an integral part of basic investigative procedures. The convenience along with high portability, rapidity, and accuracy are few of the advantages of ultrasound over the other procedures. In the last two decades, ultrasound has become an essential diagnostic imaging modality in the field of obstetrics and is being extensively used for evaluation of pregnancy. Vaginal bleeding in pregnancy especially in first trimester is a common obstetric situation ranging from an irrelevant episode to life threatening emergency. The primary causes of first trimester bleeding are spontaneous abortion, ectopic pregnancy, and gestational trophoblastic disease; however, the most common cause of bleeding is spotting caused by implantation of the conceptus into the endometrium. ${ }^{1}$ Ultrasonography is playing an increasing role in the diagnostic process. Vaginal bleeding is a common demonstration in the emergency department during the first trimester. Approximately half of patients who present with vaginal bleeding have a spontaneous abortion. $^{2}$ Recent improvements in transvaginal ultrasound permit the extremely detailed observation of the morphology of the early conceptus in utero. ${ }^{3}$ So, the rationale behind the study is to evaluate the uses of ultrasound as new diagnostic aid for patients of bleeding $\mathrm{PV}$ in pregnancy. 


\section{METHODS}

This was a hospital-based prospective study done in 100 pregnant patients admitted in labour room or antenatal wards of SRMC. The study period was of 6 months from January 2016 to June 2016.

\section{Inclusion criteria}

- $\quad$ Patients presenting anywhere from first day of last menstrual cycle to 12 weeks of pregnancy with complaints of bleeding per vagina are included in study.

\section{Exclusion criteria}

- Women having non-obstetric causes for vaginal bleeding in the first trimester of pregnancy were excluded.

- Women of reproductive age with a missed period with negative urine pregnancy test.

- Patients who refuse to get admit to the hospital.

- All patients with more than 12 completed weeks of gestation.

Purposive sampling technique was used for sampling. Demographic data such as age, parity, obstetric history, personal history, menstrual history, and details of present pregnancy such as period of amenorrhoea at the time of first episode of bleeding, amount and duration of bleeding, pain abdomen and history of expulsion of fleshy mass/clots were noted.

A detailed general physical and pelvic examination was done to arrive at a provisional clinical diagnosis. All patients were imperiled to transabdominal sonography. Ultrasonography was done using Siemens Sonoline G608 and Toshiba Nemio machines. Transvaginal sonography (TVS) was performed whenever transabdominal sonography was inconclusive or equivocal.
Transabdominal sonography was done and TVS using 5$7 \mathrm{MHz}$ transducer.

The clinical examination findings and operative procedures were noted. Clinical and ultrasound findings were correlated. After taking written informed consent from the patient's and clearly explaining the objectives the study was cleared by Institutional Ethics Committee of SRMC.

\section{Statistical analysis}

Recorded observations were analysed using Epi info software (version 7.0). The descriptive procedure was used to display univariate summary statistics for several variables in terms of frequency and Proportion. The Crosstabs procedure was used to measure of association for two-way tables. The Chi-square test was used to determine the strength of the association.

\section{RESULTS}

Table 1 shows age wise distribution of pregnant patients in which most common age group was found to be 21-30 years as $58 \%$ and the mean age group was found to be 25.4 years and was found to be statistically significant. $(\mathrm{p}=0.003)$. The total number of obstetric admissions was 1341, out of which 100 had bleeding per vagina in pregnancy constituting a percentage of $7 \%$.

Table 1: Distribution of cases according to age groups $(\mathrm{N}=100)$.

\begin{tabular}{|c|c|c|}
\hline Age groups (years) & $\mathbf{N}$ & \\
\hline$<20$ years & 17 & Mean $\pm \mathrm{SD}=25.4 \pm 4.1$ \\
\hline 21-30 years & 58 & $\chi^{2}-44.4, p=0.003^{*}$ \\
\hline $31-40$ years & 22 & \\
\hline$>40$ years & 3 & \\
\hline
\end{tabular}

Table 2: Diagnosis of bleeding per vagina in pregnancy through USG in $<20$ and $>20$ weeks $(\mathrm{N}=100)$.

\begin{tabular}{|c|c|c|c|c|}
\hline Scan (<20 weeks) & $\mathbf{N}(60)$ & Scan (>20 weeks) & $\mathbf{N}(40)$ & p-value \\
\hline Live fetus & 16 & Upper seg placenta & 9 & \multirow{9}{*}{$\begin{array}{l}0.005^{*} \\
\chi^{2}-192.3\end{array}$} \\
\hline Vesicular mole & 7 & Low lying placenta & 7 & \\
\hline Missed abortion & 3 & Partial placenta previa & 4 & \\
\hline Complete abortion & 8 & Total placenta previa & 3 & \\
\hline Incomplete abortion & 15 & Placenta localisation not possible & 2 & \\
\hline Blighted ovum & 4 & Intrauterine death & 2 & \\
\hline No gestational sac & 6 & Vesicular mole & 3 & \\
\hline Uncertain findings & 1 & Abruptio placenta & 10 & \\
\hline Abnormal scan & 0 & Partial mole & 0 & \\
\hline
\end{tabular}

$\chi^{2}$-chi-square value, ${ }^{*} \mathrm{p}<0.05$ is considered statistically significant 
Table 2 shows causes of bleeding per vagina diagnosed through USG in $<20$ and $>20$ weeks. In $<20$ weeks the most common cause was found to be live fetus followed by incomplete abortion. In scan $>20$ weeks the most common cause evaluated was abruptio placenta. And the difference was found to be statistically significant $(\mathrm{p}=0.005)$.

\section{DISCUSSION}

With ultrasound examination it has become possible to record the size and contents of uterus. In this study the main purpose of introducing ultrasound examination in cases of threatened is to identify failing gestation and thus accelerate definitive treatment.

Bleeding in early pregnancy is an indicator of an abnormality interrupting the normal development. It is a common cause for emergency admissions. If a diagnosis of the viability or non-viability of pregnancy can be made then, hormonal therapy and hospitalization can be avoided. $^{4}$

Ultrasonography has opened new dimensions in early pregnancy complications so that specific treatment, medical or surgical, can be immediately instituted.

Accurate diagnosis of the nature of the pregnancy (viable or non-viable) can avoid unnecessary hormonal treatment and prolonged hospitalisation. It also indicates the need for a dilatation and curettage by diagnosing retained products in the uterine cavity. Ultrasonographic examination should be done at the earliest possible period to confirm the clinical findings.

The incidence of bleeding in the present study was $7 \%$. $35 \%$ of patients in this study had bleeding at 6-8 weeks of gestation which is comparable to the study by Bharadwaj et al, of $30 \% .^{5}$

In the present study, abortions contributed to a major cause of the bleeding constituting $83 \%$. In a study conducted by Rani et al, also abortion was the leading cause with an incidence of $61 \%$ respectively. ${ }^{6}$ The incidence of mole in present study was $4 \%$ compared to the studies of Rani et al, an incidence of $18 \% .^{6}$

In this study, the incidence of viable pregnancies on ultrasound was $27 \%$ and $62 \%$ of non-viable pregnancies which is like the study by Schauberger et al, and Stabile et al. ${ }^{7,8}$

Ten had an incidence of $58 \%, 44 \%$, and $64 \%$ of viable pregnancies and $42 \%, 52 \%, 36 \%$ of non-viable pregnancies, respectively.

In a study conducted Rajan in a prospective study of 140 patients observed that there were 37 (26.43\%) subjects with vaginal bleeding, which was observed at or before 8 weeks in $91.89 \% .^{9}$
The sonographic landmarks of the first trimester pregnancy have been well recognised and they include identification of the gestational sac, fetal pole, fetal cardiac activity, movements, yolk sac and the amnion.

The invaluable role of these landmarks, the gestational sac and fetal biometry in diagnosing pathological pregnancies and predicting the pregnancy outcome has been clearly documented. ${ }^{10,11}$

Maihotra $\mathrm{J}$ in his prospective evaluation of 150 patients with first trimester bleeding found that ultrasonography helped in establishing the correct diagnosis in $32 \%$ of clinically misdiagnosed cases. $^{12} \mathrm{He}$ concluded that ultrasonography was the only imaging modality, by which an accurate assessment of first trimester bleeding can be done from the diagnostic and prognostic point of view.

\section{CONCLUSION}

Ultrasound is a treasured tool in the differentiation of causes of vaginal bleeding. Ultrasound is helpful in the decision-making process about the safe continuation of the pregnancy, timely intervention for abnormal pregnancy. Judicious utilization of ultrasonography and a close liaison with the sonologist is necessary.

Funding: No funding sources

Conflict of interest: None declared

Ethical approval: The study was approved by the Institutional Ethics Committee

\section{REFERENCES}

1. Dogra V, Paspulati RM, Bhatt S. First trimester bleeding evaluation. Ultrasound Q. 2005;21:69-85.

2. Paspulati RM, Bhatt S, Nour S. Sonographic evaluation of first trimester bleeding. Radiol Clin North Am. 2004;42:297.

3. Takeuchi H. Transvaginal ultrasound in the first trimester of pregnancy. Early Human Develop. 1992;29(1-3):381-4.

4. Morin L, Van den Hof MC. Diagnostic Imaging Committee, Society of Obstetricians and Gynaecologists of Canada. Ultrasound evaluation of first trimester pregnancy complications. J Obstet Gynaecol Can. 2005;27:581-91.

5. Bharadwaj N. Sonography evaluation as an aid in the management of bleeding in early pregnancy. J Obstet Gynaecol India. 1988;38:640-2.

6. Reddirani P, Sunita V. Ultrasound Evaluation of cause of vaginal bleeding in first trimester of pregnancy. J Obstet Gynecol India. 2000;50:54-8.

7. Schauberger CW, Mathiason MA, Rooney BL. Ultrasound assessment of first trimester bleeding. Obstet Gynecol. 2005;105:333-8.

8. Stabile I, Campbell S, Grudzinskas JG. Ultrasonic assessment of complications during first trimester of pregnancy. Lancet. 1987;2:1237-40. 
9. Rajan R, Rajan V. Ultrasonography in first trimester bleeding. J Obstet Gynecol India. 1987;37:457-61.

10. Tiparse A, Gandhi B, Patel A. Ultrasonographic evaluation of first trimester bleeding. Int $\mathrm{J}$ Reprod Contracept Obstet Gynecol. 2017;6:3614-7.

11. DeCherney AH, Romero R, Polan ML. Ultrasound in reproductive endocrinology. Fertil Steril. 1982;37:323.
12. Malhotra J, Saxena K, Malhotra N. Ultrasound evaluation of first trimester bleeding per vaginum. J Obstet Gynecol India. 1987;37:341-3.

Cite this article as: Sumathy KK. Diagnostic evaluation of causes of bleeding per vagina in pregnancy through ultrasonography. Int J Reprod Contracept Obstet Gynecol 2019;8:1369-72. 